\title{
OKULLARIN EĞITSEL KAYNAKLARI VE TEOG PUANLARI
}

\author{
TEOG POINTS AND EDUCATIONAL RESOURCES OF SCHOOLS
}

\section{DOI:10.17755/esosder.67084}

Emine ÖNDER ${ }^{1}$

\section{$\ddot{O} z$}

Araştırmada, okulların eğitim kaynakları incelenmiş ve eğitim kaynaklarının TEOG puanları üzerindeki etkisi belirlenmiştir. Araştırma, Burdur'da 66 ortaokul üzerinde yapılmıştır. Betimsel modeldeki araştırmada veriler, okul anketiyle toplanmıştır. Araştırmada, betimleyici ve çoklu regresyon analizleri kullanılmıştır. Analizler sonucunda, okulların finansman kaynaklarının büyük çoğunluğunun ailelerden toplanan bağışlardan elde edildiği, düşük TEOG ortalamasına sahip okullarda, öğretmen değişim hızının yüksek, rehber öğretmen bulunma ve derslerin okulun norm kadrolu branş öğretmenlerince yürütülme oranının düşük, deneyimsiz öğretmen oranının yüksek olduğu anlaşılmıştır. Okulların eğitsel kaynaklarının TEOG puanlarında yordayıcı olduğu, rehber öğretmen bulunmasının, Türkçe ve fen derslerinin okulun norm kadrolu branş öğretmenince verilmesinin TEOG ortalamalarında yüksek etkiye sahip olduğu saptanmıştır.

Anahtar Kelimeler: Okul, eğitim kaynakları, TEOG puanı.

\begin{abstract}
This research is aimed to analyse school educational resources and to determine the effect of educational resources on TEOG (Transition from Primary to Secondary Education) scores. The study was conducted on 66 secondary schools in Burdur. In the research using descriptive research model, research data was collected through the school questionnaire. In the study, descriptive and multiple regression statistical analysis were employed. As a result of the analyses, it is understood that the vast majority of financing sources of schools is obtained from donations collected from families, schools with low TEOG scores tend to have lower rate of attendance of courses by permanent staff teachers and higher rate of teacher changing, and education is provided by more inexperienced teachers. Considering the fact that educational sources are predictors on TEOG score and considering significance tests, it has been determined that presence of guidance counsellor in school, attendance of Turkish and science course by branch teachers and is significant predictor on TEOG scores of schools and these factors have the high effect on TEOG scores.
\end{abstract}

Keywords: School, educational resources, TEOG point.

\footnotetext{
${ }^{1}$ Mehmet Akif Ersoy Üniversitesi, Eğitim Fakültesi, eonder@mehmetakifedu.tr
} 


\section{GİRIŞ}

Öğrenmenin etkin bir şekilde gerçekleşmesi ve başarının sağlanabilmesi için öğrencinin kişisel ve ailevi özelliklerin dışında okulun eğitim kaynaklarının sayı ve nitelik yönünden yeterli olması gerekir. $\mathrm{Bu}$ nedenle öğrenci başarısı üzerinde okul kaynaklarının etkisi, 1966 yılında yayınlanan Eğitim Fırsatlarında Eşitlik raporundan sonra çok sayıda ülkede araştırılmıştır (Rivkin, Hanushek \& Kain, 2005). Ancak, literatürde okul kaynaklarının öğrenci başarısına etkisine dair bildirilen bulgular tutarsızdır. Bu konudaki literatür, okulun eğitim kaynağının akademik başarı üzerinde etkisinin olmadığını (Hanushek, 1997; Hanushek \& Luque, 2003; Hakkinen, Kirjavainen, \& Uusitalo, 2003) veya çok az olduğunu savunanlar ile (Demir, 2009; Hanushek, 1997, WöBmann, 2003) okul özelliklerinin öğrenci başarısındaki belirleyiciliğine açık kanıt sunanlar (Adeogun \& Osifila, 2008; Card \& Krueger, 1996; Greenwald, Hedges \& Laine, 1996) arasında ikiye bölünmüş durumdadır. Örneğin Card ve Krueger (1996), Greenwald ve diğ. (1996), Fuller ve Clarke (1994) ile Heyneman ve Loxley (1983) başarı üzerinde fiziksel ekipmanların, insani ve ekonomik kaynakların etkili olduğunu tespit etmiştir. Ferreira ve Gignoux (2010), okul ve aile özelliklerinin öğrenci fen puanının en az \%27'sine, matematik ve Türkçe puanının en az \%26'sına karş1lık geldiğini hesaplamıştır. Parsel ve Dufur (2001), daha iyi fiziksel çevreli bir okula devam etme ile artan matematik puanı arasında ilişkili olduğunu göstermiştir. Willms ve Somers (2001) öğretmen eğitimi, öğrenci-öğretmen oranı, öğretim materyalleri ve kütüphane büyüklüğü ile öğrenme çıktıları arasında pozitif yönlü anlamlı bir ilişkinin olduğunu rapor etmişlerdir. PISA 2003'de okul yöneticilerinin yaklaşık yarısı, eğitim kaynakları eksikliğinin ve nitelik açısından yetersizliğinin büyük ölçüde öğrencilerin öğrenmesini engellediğini, yaklaş1k \%80'i, alt yapısı ile ilgili fiziksel engellerin okulların öğretim kapasitesi üzerinde çok az bağlayıcı etkiye sahip olduğunu belirtmiştir (Milli Eğitim Bakanlığı [MEB], 2005). Bu bulgular Coleman Raporu ve Hanushek'in çalışmalarının bulgularıyla çelişmektedir. Bu araştırmacılar eğitime ayrılan kaynaklar ile öğrenci başarısı arasında istatistiksel olarak anlamlı bir ilişki bulunmadığı sonucuna ulaşmışlardır (Coleman, 1966; Hanushek, 2003).

Okul özelliklerinin akademik başarı üzerindeki etkisini sorgulayan bir başka araştırmada, WöBmann (2003) beklentilerin aksine, matematik ve fen başarısında sınıf büyüklügünün fazla etkisinin olmadığını, Lindahl (2005) ise İsveç’te azınlık ve ekonomik olarak dezavantajlı gruplarda sınıf büyüklüğü ile öğrenci performansı arasında önemli ilişkinin olduğunu tespit etmiştir. Lindahl'in bulguları Angrist ve Lavy (1999) ile Shin \& Raudenbush'un (2011) bulguları ile uyumludur. Bazı çalışmalarda özellikle alt sınıflarda akademik başarı üzerinde sınıf büyüklüğünün olumlu etkisi saptanmış ancak, kritik bir sınıf büyüklügü önerilmemiştir (Hanushek, Kain \& Rivkin 1998; Lindahl, 2005; Krueger, 1999; Rivkin, Hanushek \& Kain, 2005).

Sınıf büyüklüğünde olduğu gibi okul başarısı üzerinde öğretmen-öğrenci oranlarının etkilerini inceleyen çalışmaların sonuçları da tutarsızdır (Fuchs ve WöBmann, 2003; Hanushek, Rivkin \& Taylor, 1996). Demir (2009), akademik başarı üzerinde öğrenciöğretmen oranının etkisine değinmiştir. Hanushek (2003), bu alanda yapılmış çalışmaların yüzde 14'ünde öğretmen-öğrenci oranı ile öğrenci başarısı arasında pozitif ve istatistiksel olarak anlamlı bir ilişkinin bulunduğunu saptamıştır. Ayrıca konuyla ilgili yapılan çalışmalarda, akademik başarı üzerinde öğretmen yeterliklerinin etkisine işaret edilmektedir (Darling-Hammond, 2000; Fetler, 2001; Rivkin, Hanushek \& Kain, 2005). Deneyimsiz ile deneyimli öğretmenler karşılaştırıldığında, öğretmenlerin mesleki deneyimlerinin matematik başarısı üzerinde önemli bir belirleyici olduğu belirtilmektedir (Rivkin, Hanushek \& Kain, 2005). Okullar arasındaki başarı farlılıklarının, esasen öğretmen kalitesinden kaynaklandığı ve öğretmen kalitesindeki değişikliklerin, öğrenci başarısındaki farklılıkların en az yüzde 7.5'ini açıkladığı savunulmaktadır (Hanushek Kain \& Rivkin, 1998). Öğretmen eğitim 
düzeyinin (Wiseman \& Brown, 2002), hizmet süresinin ve katıldığı hizmet içi eğitimlerin, öğrencilerin akademik başarıları üzerinde önemli bir etkiye sahip olduğunu belirtilmektedir (Demir, 2009). Konuyla ilgili yapılan araştırmaların bazılarına göre ise, eğitim kaynaklarının öğrenci başarısı üzerinde etkisi ülkelerinin gelişmişlik düzeyine göre değişmektedir. Gelişmekte olan ülkelerde öğrenci başarısı ile öğrenci-öğretmen oranı, öğretmenlerin eğitim düzeyi ve deneyimi, öğretim materyallerinin mevcudiyeti ve nitelikleri ve okul tesisleri arasındaki ilişki gelişmiş ülkelerden daha belirgindir (Fuller \& Clarke, 1994; Heyneman \& Loxley, 1983). Diğer bir ifadeyle, bu ülkelerde okulun insan ve malzeme kaynakları öğrencinin başarısı üzerinde daha etkili ve daha iyi eğitim sonuçlarına ulaşmada önemli belirleyicidir. Heyneman ve Loxley (1983) düşük gelirli ülkelerde akademik başarıda okul kaynaklarının, bireysel özelliklerden çok daha fazla etkili olduğunu ve eğitimin, gelir düzeyine bağlı olduğunu öne sürmüsslerdir. Araştırmaya göre, ülkenin gelir düzeyi düştükçe okul kaynaklarının akademik başarı üzerindeki etkisi artmaktadır.

Araştırmaların bulgularından anlaşıldığı gibi, eğitsel kaynakların öğrenci başarısı üzerindeki etkisini belirlemeyi amaçlayan çalışmalarda, tek bir doğru sonuca ulaşılamamıştır. Eğitimde kullanılan girdilerin öğrenci başarısı üzerindeki etkileri, araştırmanın yapıldığı zamana, ülkeye veya bölgeye göre değişmektedir. Bu nedenle Türk Eğitim Sistemi'nde, eğitim kaynaklarının başarı üzerinde etkisinin belirlenmesinde Türkiye'nin öznel toplumsal koşullarına uygun etkenlerin göz önünde bulundurulması oldukça önemlidir. Ancak, bu çalışma kapsamında Türkiye'de yapılan alan yazın taraması sonucunda, okul ve okulun yapısal özelliklerinin okul başarısına etkisini ele alan araştırmaların sınırlı olduğu söylenebilir (Demir, 2009; Savaşç1, 2010 ve Savaşçı \& Tomul, 2013). Bu açılardan, bu araştırmanın Türkiye'de okul girdilerine yapılan yatırımın gerekçelendirilmesine yardımcı olacağı ve okulların eksikliklerinin giderilebilmesi ve toplumdaki tüm bireylerin daha nitelikli eğitime ulaşılabilmesi açısından önemli veriler sunacağı düşünülmektedir. Bu düşünceden yola çıkarak araştırmada, okulların eğitim kaynaklarının incelenmesi ve okulların eğitim kaynaklarının TEOG puanları üzerindeki yordayıcı etkisinin belirlenmesi amaçlanmıştır. Bu genel amaç doğrultusunda aşağıdaki sorulara yanıt aranmıştır.

1) TEOG puanına göre, okulların ekonomik kaynakları nasıldır?

2) TEOG puanına göre, okulların personel kaynakları nasıldır?

3) TEOG puanına göre, okulların alt yapı ve fiziki kaynakları nasıldır?

4) Okulların eğitim kaynakları TEOG puanları üzerinde anlamlı bir yordayıcı mıdır?

\section{YÖNTEM}

\subsection{Araştırmanın Modeli}

Araştırma, tarama modelindedir ve betimsel özellik taşımaktadır. Betimsel modelin en temel özelliği, mevcut durumu kendi koşulları içerisinde ve olduğu gibi ortaya koymaktır (Yıldırım ve Şimşek, 2008).

\section{2. Çalışma Grubu}

Araştırma Burdur ili ortaokulları üzerinde yapılmıştır. Ancak 12 okulun verilerine ulaşılamadığından araştırmanın çalışma grubu, 66 ortaokuldan oluşmaktadır. Çalışma grubuna ait veriler Tablo 1'de verilmiştir. 
Tablo 1. Çalışma kapsamındaki okulların dağılımı

\begin{tabular}{|c|c|c|c|c|c|c|c|c|c|}
\hline & \multicolumn{2}{|c|}{ İl Merkezi } & \multicolumn{2}{|c|}{ İlçe Merkezi } & \multicolumn{2}{|c|}{ Köy } & \multicolumn{2}{|c|}{ Toplam } \\
\hline & & $\mathrm{n}$ & $\%$ & $\mathrm{n}$ & $\%$ & $\mathrm{n}$ & $\%$ & $\mathrm{n}$ & $\%$ \\
\hline \multirow{4}{*}{ 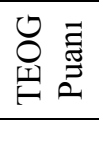 } & 299 ve alt1 & 1 & 4.5 & 4 & 18.2 & 17 & 77.3 & 22 & 33.3 \\
\hline & $300-349$ aras1 & 9 & 30 & 11 & 36.7 & 10 & 33.3 & 30 & 45.5 \\
\hline & 350 ve üzeri & 3 & 21.4 & 6 & 42.9 & 5 & 35.7 & 14 & 21.2 \\
\hline & Toplam & 13 & 19.7 & 21 & 31.8 & 32 & 48.5 & 66 & 100 \\
\hline
\end{tabular}

Tablo 1 incelendiğinde, 299 ve altı TEOG ortalamasına sahip okulların 1'inin (\%4.5) il, 4'ünün (\%18.2) ilçe merkezinde, 17'sinin (\%77.3) köyde bulunduğu görülmektedir. 300 ve 349 TEOG ortalaması aralığındaki 30 okulun 9'u (\%30) il, 11'i (\%36.7) ilçe merkezinde ve 10 'u (\%33.3) köydedir. 350 ve üzeri TEOG ortalamasına sahip okulların 3'ünün (\%21.4) il, 6'sının (\%42.9) ilçe merkezinde 5'inin (\%35.7) de köyde olduğu anlaşılmaktadır.

\subsection{Veri Toplama Aracı}

Araştırmada veri toplamak amacıyla okul anketi kullanılmıştır. Okul anketi, PISA 2012 okul anketi sorularından (OECD, 2011), okul yöneticilerinin görüşlerinden ve alan yazından faydalanılarak oluşturulmuştur. Geçerlik ve güvenirlik için, alan uzmanlarının ve okul yöneticilerinin görüşlerine başvurulmuştur. Okul anketinde, okulun alt yapı ve fiziki, ekonomik ve personel kaynaklarıyla ilgili olarak okulların özelliklerini belirlemeye yönelik maddelere yer verilmiştir. Oluşturulan anket, il merkezindeki okullarda müdürlere doğrudan araştırmacı tarafından uygulanmıştır. İlçelerde ve köylerdeki okulların müdürlerine telefonla ulaşılarak okullarına ait anketlerin bağlı oldukları Milli Eğitim Müdürlüğ̈̈'nde kendilerine ait evrak bölümlerine bırakıldığı bildirilmiş; anket ile doldurma süreci hakkında bilgi verilmiştir. Anketi doldurduktan sonra tekrar milli eğitim müdürlüklerindeki evrak bölümlerine bırakmaları istenmiştir. Anket dönüş oranını artırmak amacıyla okul yöneticileriyle telefonla irtibata geçilerek hatırlatmalar yapılmıştır. Ancak 12 okuldan dönüş olmamıştır. Okulların 2014 TEOG ortalamaları ise milli eğitim müdürlüğünden elde edilmiştir.

\subsection{Verilerin Analizi}

Araştırmada okulların eğitsel kaynakları hakkında bilgi sahibi olmak amacıyla yüzde, frekans, aritmetik ortalama ve standart sapma gibi betimleyici analizler kullanılmıştır. Okulun eğitsel kaynaklarının TEOG ortalaması üzerindeki etkisi ise çoklu regresyon ile analiz edilmiştir. Çoklu regresyon analizi yöntemlerinden aşamalı regresyon analizi kullanılmıştır.

Analiz öncesi nitel özellik taşıyan kategorik yordayıcı değişkenler dummy değişken olarak tanımlandıktan sonra analize dâhil edilmiştir. Regresyon analizinin güvenirliğini artırmak amacıyla yordayıcı değişkenler arasında çoklu bağlantılılık olup olmadığı kontrol edilmiştir. $\mathrm{Bu}$ amaçla, ilk olarak bağımsız değişkenler arasındaki ikili korelasyonlar incelenmiş ve korelasyon katsayısı .70 üzerinde olan değişkenlerden biri analize alınmıştır. Bunun yanı sıra, tolerans değerlerine, varyans büyütme faktörüne (VIF) ve durum indeksine (CI) bakılmıştır. Yordayıcı değişkenlerin tolerans değerleri .50'den büyük, VIF değerleri 10'dan ve CI değerleri 30'dan küçük olduğundan değerlerinin çoklu doğrusallık varsayımını karşıladığ1 düşünülmüştür (Büyüköztürk, 2010). Veri setinde gözlemler arasında ardışık bağımlılık (otokorelasyon) bulunup bulunmadığı anlamak için Durbin-Watson (DW) analizi yapılmıştır. Durbin-Watson değeri 2.104 olarak hesaplanmıştır. Bu katsayı 1.5-2.5 aralığında olduğundan modelde otokorelasyon sorunu olmadığını göstermektedir (Kalaycı, 2009). Uç değerlere ilişkin Mahalanobis uzaklıkları test edilmiş aşırı sapma gösteren değerler ile uç değerlere sahip beş okul veri setinden çıkarılmış ve çoklu regresyon analizi 61 okul üzerinde yapılmıştır. Anlamlılık durumu, $\mathrm{p}<0.05$ düzeyine göre değerlendirilmiştir. Bulguları yorumlamada kullanılan ortalama aralıkları, (ölçeğin aralık genişliği) dizi genişliği/yapılacak 
grup sayısı (Atılgan, 2006) formülü kullanılarak elde edilmiş ve puan aralığı 0.75 olarak belirlenmiştir. Ortalama aralıkları; hiçbir zaman engellemez 1.00-1.75, çok az engeller 1.762.50, bir dereceye kadar engeller 2.51-3.25, çok engeller 3.26-4.00 şeklindedir.

\section{BULGULAR}

Araştırmanın bu bölümünde, okulların ekonomik, personel ve altyapı-fiziki kaynaklarına ilişskin bulgulara ve okulların eğitsel kaynaklarının TEOG puanlarına etkisine yer verilmiştir.

\subsection{Okulların ekonomik kaynaklarına ilişkin bulgular}

Okulların ekonomik kaynaklarına ait bulgular Tablo 2'de verilmiştir.

Tablo 2. Okulların ekonomik kaynaklarının dağılımı (\%)

\begin{tabular}{|c|c|c|c|c|c|}
\hline & & $\begin{array}{c}\text { Okul } \\
\text { Sayısı }\end{array}$ & $\begin{array}{c}\text { Devlet Katkısı (yerel } \\
\text { yönetimler, il, bölgesel } \\
\text { ve ulusal gelirler dahil) }\end{array}$ & $\begin{array}{c}\text { Ailelerden } \\
\text { Toplanan Paralar } \\
\text { ve Bağışlar }\end{array}$ & Diğer \\
\hline \multirow{4}{*}{ 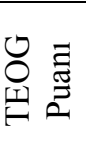 } & 299 ve altı & 22 & 8.74 & 73.58 & 17.67 \\
\hline & $300-349$ & 30 & 9.17 & 82.00 & 8.83 \\
\hline & 350 ve üzeri & 14 & 4.93 & 82.04 & 13.03 \\
\hline & Toplam & 66 & 8.11 & 79.28 & 12.61 \\
\hline
\end{tabular}

TEOG ortalamalarına göre bir değerlendirme yapıldığında durumun değişmediği görülmektedir. Ailelerden toplanan para ve bağışların (299 ve altında \%73.58, 300-349 arasında \%82, 350 ve üzerinde \%82.04) oldukça yüksek, devlet katkısının (299 ve altında $\% 8.74,300-349$ arasında \%9.17, 350 ve üzerinde \%4.93) ise oldukça düşük olduğu söylenebilir. Araştırmanın okul gelirleriyle ilgili veriler toplanırken tüm okulların devletçe karşılanan yakacak, elektrik, su ve internet gibi giderleri çıkarıldığında devletin okullara olan katkısı belirlenmiştir. Dolayısıyla, devlet katkısı düşüklüğünün bundan kaynaklandığı düşünülmektedir. Ayrıca, bulgulardan yola çıkıldığında, belirtilen harcama kalemleri dışında okulların mali gücünün, öğrencilerin sosyo-ekonomik durumuna bağlı olduğu ve okulların imkanlarının doğrudan öğrencilerin sosyo-ekonomik düzeyleri ile ilintili olduğu söylenebilir.

\subsection{Okulların personel kaynaklarına ilişkin bulgular}

Okulların personel kaynaklarına ait bulgular Tablo 3 ve Tablo 4'te verilmiştir.

Tablo 3. Okullarda öğretmenlerin görev süresi-rehber öğretmen durumu

\begin{tabular}{lccccccc}
\hline $\begin{array}{c}\text { Ortalama } \\
\text { TEOG } \\
\text { Puanı }\end{array}$ & $\begin{array}{c}\text { Okul } \\
\text { Sayısı }\end{array}$ & \multicolumn{2}{c}{$\begin{array}{c}\text { Öğretmen } \\
\text { Deneyimi (yıl) }\end{array}$} & $\begin{array}{c}\text { Öğretmenin Aynı Okulda } \\
\text { Çalışma } \\
\text { Uzunluğu (yıl) }\end{array}$ & \multicolumn{2}{c}{$\begin{array}{c}\text { Okulda Rehber } \\
\text { Öğretmen } \\
\text { Bulunma Durumu }\end{array}$} \\
\hline & $\mathbf{n}$ & $\overline{\mathrm{X}}$ & $\mathbf{S s}$ & $\overline{\mathrm{X}}$ & $\mathbf{S s}$ & $\mathbf{V a r}$ & Yok (\%) \\
\hline 299 ve altı & 22 & 6.14 & 2.32 & 3.27 & 1.57 & 13.6 & 86.4 \\
300 ile 349 & 30 & 8.63 & 3.73 & 5.13 & 2.3 & 40 & 60 \\
350 ve & 14 & 9.43 & 4.49 & 5.43 & 3.13 & 64.3 & 35.7 \\
Toplam & 66 & 8.30 & 3.57 & 4.91 & 2.44 & 36.4 & 63.6 \\
\hline
\end{tabular}

Tablo 3 incelendiğinde, 299 ve altında TEOG ortalamasına sahip okullarda öğretmen kıdeminin $(\bar{x}=6.14)$, aynı okulda ortalama görev yapma süresinin $(\bar{x}=3.27)$ ve rehber öğretmen bulunma oranının en düşük (\%13.6) düzeyde olduğu görülmektedir. 350 ve üzeri TEOG ortalamalı okullarda, öğretmen kıdemi $(\bar{x}=9.43)$, aynı okulda ortalama görev yapma süresi $(\bar{x}=5.43)$ ve rehber öğretmen bulunma oranı en yüksek $(\% 64.3)$ düzeydedir. 
TEOG puanlarına göre, okulların öğretmen istihdam biçimleri Tablo 4'te verilmiştir.

Tablo 4. Okulların ders bazında öğretmen dağılımları

\begin{tabular}{|c|c|c|c|c|c|c|}
\hline & & $\begin{array}{l}\text { Branş (Norm } \\
\text { Kadro) }\end{array}$ & $\begin{array}{c}\text { Branş } \\
\text { (Görevlendirme) } \\
\end{array}$ & $\begin{array}{c}\text { Branş } \\
\text { (Ǘcretli) }\end{array}$ & $\begin{array}{l}\text { Farklı Branş } \\
\text { (Norm Kadro) }\end{array}$ & $\begin{array}{l}\text { Farklı Branş } \\
\text { (Ücretli) }\end{array}$ \\
\hline \multirow{6}{*}{ 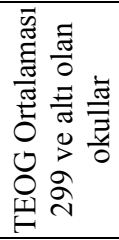 } & Türkçe & 81.8 & 4.5 & 9.1 & - & 4.5 \\
\hline & Matematik & 77.3 & 9.1 & 9.1 & 4.5 & - \\
\hline & Fen ve Teknoloji & 72.7 & 9.1 & 18.2 & - & - \\
\hline & Sosyal Bil. & 95.5 & 4.5 & - & - & - \\
\hline & Yabancı Dil & 72.7 & 13.6 & 9.1 & - & 4.5 \\
\hline & Din Kül. ve Ahlak Bil. & 68.2 & 13.6 & 9.1 & 9.1 & - \\
\hline \multirow{6}{*}{ 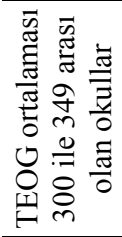 } & Türkçe & 100 & - & - & - & - \\
\hline & Matematik & 96.7 & - & 3.3 & - & - \\
\hline & Fen ve Teknoloji & 90 & 6.7 & 3.3 & - & - \\
\hline & Sosyal Bil. & 93.3 & 3.3 & 3.3 & - & - \\
\hline & Yabancı Dil & 83.3 & 3.3 & 13.3 & - & - \\
\hline & Din Kül. ve Ahlak Bil. & 71.4 & 7.1 & - & 14.3 & 7.1 \\
\hline \multirow{6}{*}{ 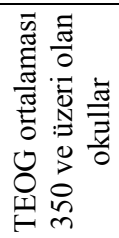 } & Türkçe & 100 & - & - & - & - \\
\hline & Matematik & 100 & - & - & - & - \\
\hline & Fen ve Teknoloji & 100 & - & - & - & - \\
\hline & Sosyal Bilgiler & 92.9 & 7.1 & - & - & - \\
\hline & Yabancı Dil & 92.9 & - & - & - & 7.1 \\
\hline & Din Kül ve Ahlak Bil. & 80 & 6.7 & 6.7 & 6.7 & - \\
\hline
\end{tabular}

Tablo 4'e göre, 299 ve altı TEOG ortalamalı okullarda Türkçe (\%81.8), matematik (\%77.3), fen ve teknoloji (\%72.7), sosyal bilgiler (\%95.5), yabancı dil (\%72.7) ve din kültürü ve ahlak bilgisi (\%68.2) dersinin okulun norm kadrolu branş öğretmenince yürütülme oranı daha yüksek TEOG ortalamalı okullardan düşüktür. TEOG ortalaması 300-349 olan okullarda Türkçe'nin \%100'ü, matematiğin \%96.7'si, fen ve teknolojinin \%90'1, sosyal bilgilerin \%93.3'ü, yabancı dilin \%83.3'ü ve din kültürü ve ahlak bilgisinin \%71.4'ü okulun norm kadrolu branş öğretmenince verilmektedir. 350 ve üzeri TEOG ortalamasına sahip okullarda ise Türkçe, matematik, fen ve teknoloji derslerinin \%100'ü, sosyal bilgiler ve yabancı dil derslerinin \%92.9'u ile din kültürü ve ahlak bilgisi dersinin \%80'i okulun norm kadrolu branş öğretmenlerince yürütülmektedir. Tablo tersten okunduğunda, en düşük TEOG ortalamalı okullarda derslerin yaklaşık üçte birinin farklı okuldan görevlendirilen branş öğretmeni veya ücretli branş öğretmeni ile değişik statüde çalışan farklı branştan öğretmenler tarafindan yürütüldüğü söylenebilir.

\subsection{Okulların altyapı ve fiziki kaynaklarına ilişkin bulgular}

Okulların altyapı fiziki kaynaklarına ait bulgular Tablo 5 'te verilmiştir.

Tablo 5. Okulların altyapı ve fiziki kaynakları

\begin{tabular}{|c|c|c|c|c|c|c|c|c|c|}
\hline \multirow{2}{*}{ TEOG Puanı } & \multicolumn{3}{|c|}{299 ve altı } & \multicolumn{3}{|c|}{300 ile 349 arası } & \multicolumn{3}{|c|}{350 ve üzeri } \\
\hline & $\mathbf{n}$ & $\overline{\mathrm{X}}$ & Ss & n & $\overline{\mathrm{X}}$ & Ss & n & $\overline{\mathrm{X}}$ & Ss \\
\hline Fen laboratuvarı eksikliği & 22 & 2.09 & 1.02 & 30 & 1.87 & 1.25 & 14 & 2.36 & 1.22 \\
\hline $\begin{array}{l}\text { Fen laboratuvarı araçlarının } \\
\text { eksikliği / uygun olmaması }\end{array}$ & 22 & 2.82 & 0.96 & 30 & 2.27 & 1.14 & 14 & 2.71 & 1.27 \\
\hline $\begin{array}{l}\text { Matematik dersi araçlarının } \\
\text { eksikliği / uygun olmaması }\end{array}$ & 22 & 2.68 & 0.89 & 30 & 2.10 & 1.06 & 14 & 2.21 & 1.05 \\
\hline $\begin{array}{l}\text { Sosyal bilgiler dersi araçlarının } \\
\text { eksikliği / uygun olmaması }\end{array}$ & 22 & 2.73 & 0.77 & 30 & 1.97 & 1.07 & 14 & 2.07 & 1.07 \\
\hline $\begin{array}{l}\text { Öğretim materyallerinin eksikliği } \\
\text { / uygun olmaması }\end{array}$ & 22 & 2.64 & 1.00 & 30 & 2.33 & 1.06 & 14 & 2.43 & 1.02 \\
\hline $\begin{array}{l}\text { Projeksiyon, fotokopi, yazıcı gibi } \\
\text { donanımların eksikliği / uygun } \\
\text { olmaması }\end{array}$ & 22 & 2.50 & 1.19 & 30 & 2.27 & 1.23 & 14 & 2.00 & 1.30 \\
\hline Bilgisayar odası eksikliği & 22 & 2.14 & 1.28 & 30 & 1.73 & 1.01 & 14 & 1.57 & 0.94 \\
\hline
\end{tabular}




\begin{tabular}{lccccccccc}
$\begin{array}{l}\text { Öğretime ayrılmış bilgisayarların } \\
\text { eksikliği / uygun olmaması }\end{array}$ & 22 & 2.82 & 1.05 & 30 & 2.53 & 1.22 & 14 & 2.64 & 1.01 \\
$\begin{array}{l}\text { Internet bağlantısının } \\
\text { bulunmaması / yeterli olmaması }\end{array}$ & 22 & 2.50 & 1.22 & 30 & 2.23 & 1.19 & 14 & 2.29 & 1.14 \\
$\begin{array}{l}\text { Öğretimle ilgili bilgisayar } \\
\text { yazılımlarının eksikliği / uygun } \\
\text { olmaması }\end{array}$ & 22 & 2.36 & 1.00 & 30 & 2.43 & 1.07 & 14 & 2.36 & 1.22 \\
$\begin{array}{l}\text { Kütüphanedeki kitap veya } \\
\text { materyallerin eksikliği/uygun } \\
\text { olmaması }\end{array}$ & 22 & 2.73 & 1.03 & 30 & 2.40 & 1.13 & 14 & 2.21 & 1.25 \\
$\begin{array}{l}\text { Görsel işitsel kaynakların } \\
\text { eksikliği / uygun olmaması }\end{array}$ & 22 & 2.77 & 0.97 & 30 & 2.70 & 1.09 & 14 & 2.21 & 1.12 \\
$\begin{array}{l}\text { Spor salonu eksikliği/uygun } \\
\text { olmaması }\end{array}$ & 22 & 3.50 & 0.73 & 30 & 3.32 & 0.84 & 14 & 3.00 & 1.24 \\
$\begin{array}{l}\text { Oyun alanı eksikliği/uygun } \\
\text { olmaması }\end{array}$ & 22 & 2.50 & 1.06 & 30 & 2.10 & 0.99 & 14 & 2.71 & 1.14 \\
\hline
\end{tabular}

Tablo 5 incelendiğinde, okulların altyapı ve fiziki kaynaklarına ilişkin en yüksek ortalamaların 299 ve altı TEOG puanlı okullara ait olduğu söylenebilir. Okulların TEOG ortalamaları yükseldikçe altyapı ve fiziki kaynaklara ait eksikliğin ya da uygun olmama durumunun azaldığ 1 görülmektedir. 299 ve altı TEOG ortalamasına sahip okullarda, öğretimin kapasitesini en fazla engelleyen durumlar arasında ilk üç sırada spor salonunun eksiliği veya uygun olmaması $(\bar{x}=3.50)$, fen laboratuvarı araçlarının eksikliği ya da uygun olmaması $(\bar{x}=$ 2.82) ve öğretime ayrılmış bilgisayarların eksikliği ya da uygun olmaması $(\bar{x}=2.82)$ gösterilmiştir. Bu okullarda öğretim kapasitesini en az engelleyen altyapı ve fiziki kaynak, fen laboratuvarı $(\bar{x}=2.09)$ ve bilgisayar odası $(\bar{x}=2.14)$ eksikliğidir. $300-349$ arası TEOG ortalamasına sahip okullarda ise, spor salonu $(\bar{x}=3.32)$ ve görsel-işitsel $(\bar{x}=2.70)$ kaynakların eksikliği ya da uygun olmaması en fazla, bilgisayar odası eksikliği ( $\bar{x}=1.73)$ en az engelleyen durumdur. 350 ve üzeri TEOG ortalamasına sahip okullarda spor salonu ( $\bar{x}=$ 3.00) ile oyun alanı eksikliği veya uygun olmaması $(\bar{x}=2.71)$ okulun öğretim kapasitesini en fazla, bilgisayar odası eksikliği $(\bar{x}=1.57)$ ile projeksiyon, fotokopi makinası, yazıcı gibi donanımların eksikliği ya da uygun olmaması $(\bar{x}=2.07)$ en az engelleyen altyapı ve fiziki durum olarak belirtilmiştir. Ayrıca, Tablo 5 incelendiğinde, 350 ve üzeri TEOG ortalamasına sahip okullarda oyun alanı eksikliği ya da uygun olmaması ortalamasının diğer okullardan yüksek olduğu görülmektedir. Fen laboratuvarı araçlarının $(\bar{x}=2.71)$, matematik $(\bar{x}=2.21)$ ve sosyal bilgiler $(\bar{x}=2.07)$ dersi araçlarının eksikliği ya da uygun olmaması ortalamaların ise 300 ve üzeri TEOG ortalamasına sahip okullardan yüksek olduğu anlaşılmaktadır. Sonuçların bu yönlü olmasının, 350 ve üzeri ortalamaya sahip okulların büyük okullar olması nedeniyle daha çok öğrenciye hizmet vermesi, bu okulların il ve ilçe merkezlerinde veya yaşamın ve trafiğin yoğun olduğu alanlarda bulunmasından kaynaklandığı düşünülmektedir.

\subsection{Eğitim kaynaklarının TEOG puanları üzerinde etkisi}

Okulların eğitim kaynaklarının TEOG ortalamalarına ilişkin regresyon sonuçları Tablo 6'da verilmiştir.

Tablo 6. Okulların eğitim kaynaklarının TEOG puanları üzerindeki etkisi

\begin{tabular}{|c|c|c|c|c|c|c|c|}
\hline Değişken & B & Ss & $\boldsymbol{\beta}$ & $\mathbf{t}$ & $\mathbf{p}$ & İkili $\mathbf{r}$ & Kismi r \\
\hline Sabit & 246.632 & 26.103 & - & 9.448 & .000 & 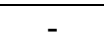 & - \\
\hline Altyapı-fiziki donanım & 4.306 & 4.931 & .101 & .873 & .387 & . 007 & .120 \\
\hline $\begin{array}{l}\text { Matematik (Norm kadrolu } \\
\text { branş öğretmenince verilme } \\
\text { durumu) }\end{array}$ & -12.584 & 8.465 & -.190 & -1.487 & .143 & .057 & -.202 \\
\hline $\begin{array}{l}\text { Fen (Norm kadrolu branş } \\
\text { öğretmenince verilme durumu) }\end{array}$ & 25.611 & 12.265 & 260 & 2.088 & .042 & .352 & 278 \\
\hline Sosyal (Norm kadrolu branș & -11.264 & 16.562 & -.084 & -.680 & .499 & .052 & -.094 \\
\hline
\end{tabular}




\begin{tabular}{|c|c|c|c|c|c|c|c|}
\hline $\begin{array}{l}\text { İngilizce (Norm kadrolu branş } \\
\text { ögretmenince verilme durumu) }\end{array}$ & -5.551 & 10.374 & -.064 & -.535 & .595 & .141 & -.074 \\
\hline $\begin{array}{l}\text { Okulda rehber öğretmen } \\
\text { bulunma }\end{array}$ & 35.877 & 8.163 & .524 & 4.395 & .000 & .491 & .520 \\
\hline $\begin{array}{l}\text { Türkçe (Norm kadrolu branş } \\
\text { öğretmenince verilme durumu) }\end{array}$ & 34.977 & 17.309 & .260 & 2.021 & .048 & .288 & .270 \\
\hline $\begin{array}{l}\text { Din kül. ve ahlak bilgisi (Norm } \\
\text { kad. branş öğret. verilme } \\
\text { durumu) }\end{array}$ & -1.643 & 9.389 & -.022 & -.175 & .862 & .163 & -.024 \\
\hline Okulun diğer gelirleri & 16.069 & 15.274 & .119 & 1.052 & .298 & .046 & .144 \\
\hline
\end{tabular}

Tablo 6 incelendiğinde, okulun eğitsel kaynaklarının, öğrenci başarısı üzerine anlamlı yordayıı1 $\left(\mathrm{R}=.634 \mathrm{R}^{2}=.402\right)$ olduğu görülmektedir $\left(\mathrm{F}_{(9-52)}=3.891, \mathrm{p}<.01\right)$. Söz konusu değişkenler birlikte TEOG puanındaki değişimin \%40'ını açıklamaktadır. Beta değerleri dikkate alındığında yordayıcı değişkenlerden TEOG puanları üzerinde en etkili olanlar; okulda rehber öğretmen bulunması $(\beta=.524)$, Türkçe ve fen dersleri $(\beta=.260)$ ile matematik dersinin $(\beta=-.190)$ okulun norm kadrolu branş öğretmenince verilmesi, okulun diğer gelir kaynakları $(\beta=.119)$, okulun fiziki olanakları ve eğitim materyalleri $(\beta=.101)$ şeklinde sıralanmaktadır. Regresyon katsayılarının anlamlılığına ilişkin t-testi sonuçları incelendiğinde ise, sadece okulda rehber öğretmen bulunması, Türkçe ve fen derslerinin okulun norm kadrolu branş öğretmenince verilmesinin TEOG puanları üzerinde anlamlı bir yordayıcı olduğu görülmektedir $(\mathrm{p}<.05)$. Diğer yordayıcı değişkenler okulun TEOG puan ortalaması üzerinde önemli bir etkiye sahip değildir. Yordayıcı değișkenlerle yordanan değişken arasındaki ikili ve k1smi korelasyonlar incelendiğinde, TEOG puanı ile okulda rehber öğretmen bulunma $(\mathrm{r}=0.49)$ ve fen dersinin okulun norm kadrolu branş öğretmenince verilme durumu $(\mathrm{r}=0.35)$ arasında pozitif ve orta düzeyde bir ilişkinin olduğu, ancak diğer değişkenler kontrol edildiğinde TEOG puanı ile okulda rehber öğretmen bulunma durumu arasındaki korelasyonun $\mathrm{r}=0.52$, fen dersinin okulun norm kadrolu branş öğretmenince verilme durumu arasındaki korelasyonun $\mathrm{r}=0.28$ olarak hesaplandığı görülmektedir. Diğer yordayıcı değişkenlerle yordanan değişken arasındaki ilişki düşük düzeydedir.

\section{TARTIŞMA VE SONUÇ}

Bu çalışmada okulların eğitim kaynakları incelenmiş ve okulların eğitim kaynaklarının TEOG puanları üzerinde yordayıcı etkisi belirlenmiştir. Elde edilen bulgular incelendiğinde, okul gelirlerinin büyük bir bölümünün ailelerden toplanan paralar ve bağışlar yoluyla elde edildiği anlaşılmaktadır. Ulaşılan bu sonuç, Savaşçı ve Tomul'un (2013) sonuçlarıyla örtüşmektedir. Araştırmacılar, okulların mali kaynaklarını ağırlıklı olarak devlet dışında farklı kaynaklardan elde ettiklerini tespit etmişlerdir (okul gelirlerinin \%53.41'i öğrenci ücretleri ya da aileler tarafından ödenen okul aidatlarınca, \%25.32'si bağışlardan, \%15.61'i ise devlet tarafından karşılanmaktadır). Türkiye'de ilköğretim okullarına doğrudan bir bütçe aktarımı olmamakla birlikte, okulların yakacak, elektrik, su ve internet giderleri devlet tarafından karşılanmaktadır. $\mathrm{Bu}$ giderler dahil edilmediğinde, okulların mali gücünün öğrencilerin sosyoekonomik durumuna bağlı olduğu, dolayısıyla okulların imkanlarının doğrudan öğrencilerin sosyoekonomik düzeylerine göre şekillendiği söylenebilir. Türkiye'de aileler gelirlerinin \%1'i ile \%15'i arasında bir oranı eğitime ayırmaktadır (Tansel \& Bircan, 2006). Ancak en zengin \%20'lik dilimin eğitim harcamaları en yoksul \%20'lik dilimin eğitim harcamalarının 21 kat üzerindedir (Eğitim Reformu Girişimi [ERG], 2009). Bu durum daha yüksek sosyoekonomik düzeyden öğrencilere hizmet veren okulların daha yüksek mali güce sahip olmasına, bu okulların alt yapı, fiziki olanaklarının ve eğitim materyallerinin niteliğinin yükselmesine yol açabilir. Bu nedenle, MEB tarafından tüm devlet okullarının aynı giderleri karşılansa bile, ailelerin yaptıkları fazladan harcamalar farklı sosyoekonomik gruplar arasında hâlihazırda var olan eşitsizlikleri pekiştirebilir. Zaten avantajlı olan öğrencileri daha avantajlı duruma getirebilir ve eğitimde firsat ve imkan eşitliğinin önünde ciddi engeller oluşturabilir. 
$\mathrm{Bu}$ sebepten ailelerce sağlanan eğitim gelirleri hesaplanarak, Türkiye'de kaynakların etkin kullanımı veya dağıtımı yani eğitim harcamalarındaki verimliliği tekrar gözden geçirilmelidir.

Araștırma bulgularına göre, düşük TEOG ortalamasına sahip okullarda öğretmenler daha az deneyimli ve öğretmen öğrenci oranları ile rehber öğretmen bulunma oranları oldukça düşüktür. Aynı zamanda bu okullarda derslerin okulun norm kadrolu branş öğretmenince verilme oranı da, yüksek TEOG ortalamasına sahip okullardan oldukça düşüktür. Bir başka ifadeyle, bu okullarda dersler farklı okullardan görevlendirilen branş öğretmenleri veya ücretli branş öğretmenleri ya da değişik statüde çalışan farklı branştan öğretmenler tarafından yürütülmektedir. Öğrencilere daha tecrübesiz öğretmenlerle hizmet verilmektedir. Ayrıca rehber öğretmen bulunmadığından, öğrenilmiş başarısızlıkla ve sınav kaygısıyla baş edebilme, çalışma planı yapabilme, iyi çalışma alışkanlıkları kazanma, derse aktif katılma gibi konularda öğrencilerin destek alamadıkları söylenebilir. Araştırmanın bu sonuçlarının, öğretmen deneyimi ve yeterliklerinin başarı üzerinde belirleyici olduğuna işaret ettiği söylenebilir. Alan yazında da, akademik başarı üzerinde öğretmen yeterliklerinin etkisine işaret edilmekte (Darling-Hammond, 2000; Fetler, 2001; Ferguson, 1991; Rivkin, Hanushek \& Kain, 2005), okullar arasındaki başarı farklılıklarının, esasen öğretmen kalitesinden kaynaklandığı bildirilmektedir (Hanushek ve diğ., 1998; Rockoff, 2004). Öğretmenlerin hizmet süresinin öğrencilerin akademik başarıları üzerinde önemli etkiye sahip olduğu belirtilmektedir (Demir, 2009). Bir ile üç yıllık tecrübeye sahip deneyimsiz öğretmenlerle deneyimli öğretmenler karşılaştırıldığında, öğretmen tecrübesinin başarı üzerinde önemli bir etkide bulunduğu vurgulanmaktadır (Rivkin, Hanushek \& Kain, 2005). Bu bakımdan araştırmanın bu yönüyle literatürle uyumlu olduğu söylenebilir.

Araştırmada, düşük TEOG ortalamasına sahip okullarda alt yapı ve eğitim materyali eksikliğinin veya uygun olmamasının daha yüksek TEOG puanlı okullardan yüksek olduğu belirlenmiş olsa da hemen hemen tüm okullarda altyapı ve fiziki kaynak eksikliği ya da uygun olmama durumunun eğitimi çok az engeller düzeyde olduğu görülmektedir. $\mathrm{Bu}$ yönüyle araştırma PISA (2003) raporuyla uyumludur. Raporda, fiziksel kaynak eksikliğinin öğrenci performansını olumsuz yönde etkilediği ve öğrencilerin öğrenmesini engellediği belirtilmekle birlikte, fiziksel engellerin okulların öğretim kapasitesi üzerinde çok az bağlayıcı etkisi olduğu belirtilmektedir (MEB, 2005). Hanushek (1997), Hanushek ve Luque (2003), Hakkinen ve diğerleri (2003) araştırmalarında, okulun fiziksel kaynaklarının öğrencilere daha yüksek performans kazandırmadığını tespit etmişlerdir. Gerek bu araştırmanın gerekse konuyla ilgili diğer araștırmaların bulguları özetlendiğinde, okulun altyapı ve fiziki olanakları ile başarı arasında güçlü bir ilişkiden bahsetmenin mümkün olmadığı söylenebilir. Ayrıca altyapı ve fiziki kaynak açısından, düşük ve yüksek TEOG ortalamasına sahip okullar karşılaştırıldığında, 350 ve üzeri TEOG puanına sahip okullarda, oyun alanı eksikliği ya da uygun olmaması hariç, fiziksel donanımdan ziyade eğitim materyallerine yönelik sıkıntılarının daha yoğun olduğu söylenebilir. Bu sonuçlar, TEOG ortalaması yüksek olan okulların büyük okullar olması, dolayısıyla, daha çok öğrenciye hizmet vermesi ve genellikle il ve ilçe merkezlerinde yaşamın ve trafiğin yoğun olduğu alanlarda bulunmasından kaynaklanmış olabileceğini düşündürmektedir.

Araștırmada, okulun eğitsel kaynakların bir bütün olarak TEOG ortalaması üzerinde anlamlı yordayıcıdır. TEOG puanındaki değişimin yaklaşık \%40'ının okulun eğitsel kaynaklarınca açıklandığı anlaşılmaktadır. Araştırmada okulun eğitsel kaynaklarının başarı üzerindeki varyasyon oranının bazı araştırmalarda saptanandan yüksek olması araştırmada modele dahil edilen yordayıcı değişken sayısının çokluğuna bağlanmıştır. Ayrıca, öğrencilerin içinden geldikleri sosyoekonomik koşullarının yansıması da sonuçların bu yönlü olmasında belirleyici olabilir. Nitekim konuyla ilgili araştırmaların birinde, başarı farklılığının \%1.4 ile \%7.5 arasında bir bölümünün okul ortamının net etkisiyle açıklanabileceği, ancak, okul ortamı öğrencilerin sosyoekonomik ortam ile birlikte ele alındığında, oranın \%29 ile \%49'a ulaşabileceği belirtilmiştir (MEB, 2005). Bacolod \& Tobias (2006) göre de, okullar toplam varyasyonun yaklaşı \% \%4.4-\%5.3'ünü açıklıyor olsa da araştırmacılar okulların başarı üzerinde belirleyiciliğinin önemine dikkat çekmiştir. Bazı araştırmalarda, Yunanistan, Norveç ve Türkiye gibi ülkelerde bu tür eksikliklerin okulun öğretim kapasitesi üzerindeki sınırlayıcı etkisinin beklenilenin üstünde olduğu belirtilmektedir (MEB, 2005). Ülkelerin gelișmișlik durumuna göre farklılık gösterse de, eğitim kaynaklarının başarıda sosyoekonomik faktörlerin 
etkisini azaltarak öğrencilere firsat eşitliği sağlamada önemli rol oynadığı bildirilmektedir (UNESCO, 2007). Bu durumda, okullar arası performans farklılıklarının, okul temelli kaynakların varlığı, kullanımı ve yönetimine bağlı olarak değişebileceği söylenebilir.

Araştırmada, okulda rehber öğretmenin bulunması ve fen derslerinin okulun norm kadrolu branş öğretmenlerince verilmesi yordayıcı değişkenlerin TEOG puanları üzerinde anlamlı yordayıcı olduğu görülmüştür. Ayrıca bu değişkenler dışında, Türkçe ve matematik derslerinin okulun norm kadrolu branş öğretmenince verilmesi yordayıcı değişkenlerinin TEOG puanı üzerindeki göreli önem sıralarının da yüksek olduğu saptanmıştır. Araştırmanın bu bulgusu, bir kez daha, öğretmen faktörünün kaliteyi geliştirme sürecinde temel çıkış noktası, her şeyin başı olduğunu ortaya koymuştur. Öğrencilerin gelişimleri ve başarıları üzerindeki öğretmen yeterliklerinin olumlu etkisine dikkatleri çekmiștir. $\mathrm{Bu}$ bakımdan öğretmen yeterliği ve öğretmenlerin geliştirilmesi ve nitelikli öğretmenlerin istihdam edilmesi eğitim sistemimiz açısından büyük önem taşımaktadır.

Araştırma sonuçları doğrultusunda şu önerilerde bulunulmuştur: Eşitlik adaleti getirmeyeceğinden, finansal ve diğer kaynaklar, dezavantajlı öğrencilerin yoğunlukla bulunduğu okullara sosyoekonomik eşitsizliklerin eğitime etkisini azaltacak şekilde dağıtılabilir. Dezavantajlı çevrelerdeki okulların öğretmen değişim hızını düşürmek ve nitelikli, tecrübeli, alanında uzman öğretmenlerin bu okullarda uzun süre çalışmasını sağlayabilmek için; bu okulların, çalışma koşulları iyileştirilebilir. Bu kurumlarda görev yapan öğretmenlere, ek ücret ve hizmet puanı vb. gibi teşvikler verilebilir Yine öğretmen atamaları, sadece açığı giderme temeline dayandırılmadan, diğer bir ifadeyle, zaten değissik açılardan dezavantajlı öğrenciler ile deneyimsiz öğretmenlerin buluşmasını engelleyici bir düzenleme ile yapılabilir. Burdur ili ile sınırlı olan bu araştırma sonuçları Türkiye evrenini temsil edecek yeni araştırmalarla sınanabilir ve genişletilebilir.

\section{KAYNAKÇA}

Adeogun, A. A., \& Osifila, G. I. (2008). Relationship between educational resources and students' academic performance in Lagos State Nigeria. International Journal of Educational Management, 5(6), 144-153.

Angrist, J. D. \& Lavy, V. (1999). Using maimonides' rule to estimate the effect of class size on scholastic achievement. The Quarterly Journal of Economics, 114, 533-575. http://dx.doi.org/10.1162/003355399556061

Atılgan, H. (2006). Eğitimde ölçme ve değerlendirme. Ankara: Anı Yayıncılık.

Bacolod, M. \& Tobias, J., (2006). Schools, School Quality and Academic Achievement: Evidence from the Philippines, Economics of Education Review, 25(6), 619-632.

Card, D., \& Krueger, A. (1996). School resources and student outcomes: An overview of the literature and new evidence from North and South Carolina. Journal of Economic Perspectives, 10, 31-40. http://dx.doi.org/10.1257/jep.10.4.31

Darling-Hammond, L. (2000). Teacher quality and student achievement: A review of state policy evidence. Education Policy Analysis Archives, 8(1).

Demir, C. E. (2009). Factors influencing the academic achievement of the Turkish urban poor. International Journal of Educational Development, 29, 17-29. http://dx.doi.org/10.1016/j.ijedudev.2008.03.003

ERG (2009). Eğitimde eşitlik politika analizi ve öneriler. İstanbul. http://www.erg.sabanciuniv.edu.

Ferreira, F. H. G., \& Gignoux, J. (2010). Inequality of opportunity for education: The case of Turkey. State Planning Organization of the Republic of Turkey and World Bank. Working Paper Number: 4. 
Fetler, M. (2001). Student mathematics achievement test scores, dropout rates, and teacher characteristics. Teacher Education Quarterly, 151-168.

Fuller, B. \& Clarke, P. (1994). Raising school effects while ignoring culture? Local conditions and the influence of classroom tools, rules and pedagogy. Review of Educational Research, 64, 122-131.

Gamoran, A., \& Willms, J. D. (2001). Class size and student achievement. Psychological Science in the Public Interest, 2(1), 1-30.

Greenwald, R., Hedges, L.V., \& Laine, R. (1996). The effect of school resources on student achievement. Review of Educational Research, 66, 361-396.

Hakkinen, I., Kirjavainen, T., \& Uusitalo, R. (2003). School resources and student achievement revisited: New evidence from panel data. Economics of Education Review, 22, 329-335. http://dx.doi.org/10.1016/S0272-7757(02)00060-2

Hanushek, E. A., Kain, J. F. \& Rivkin, S. G. (1998). Teachers school and academic achievement, National Bureau of Economic Research, Working Paper 6691.

Hanushek, E. A. (2003). The failure of input based schooling policies, The Economic Journal 113.

Hanushek, E. A., \& Luque, J. A. (2003). Efficiency and equity in schools around the world. Economics of Education Review, 22, 481-502. http://dx.doi.org/10.1016/S02727757(03)00038-4

Hanushek, E. A. (1997). Assessing the effects of school resources on student performance: An update. Educational Evaluation and Policy Analysis, 19(2), 141-164.

Hanushek, E. A., Rivkin, S. G., \& Taylor, L. L. (1996). Aggregation and the estimated effects of school resources. The Review of Economics and Statistics, 78(4), 611-627. http://dx.doi.org/10.2307/2109949

Heyneman, S. P., \& Loxley, W. A. (1983). The effect of primary school quality on academic achievement across 29 high- and low-income countries. American Journal of Sociology, 88(6), 1162-1194. http://dx.doi.org/10.1086/227799

Kalaycı, Ş. (2009). SPSS uygulamalı çok değişkenli istatistik uygulamaları. Ankara: Asil Yayınevi.

Krueger, A. (1999). Experimental estimates of education production functions. The Quarterly Journal of Economics, 114, 497-532. http://dx.doi.org/10.1162/003355399556052

Lindahl, M. (2005). Home versus school learning: A new approach to estimating the effect of class size on achievement. Scandinavian Journal of Economics, 107(2), 375-394. http://dx.doi.org/10.1111/j.1467-9442.2005.00413.x

MEB (2005). PISA 2003 projesi ulusal nihai rapor. MEB, ANKARA.

OECD (2011). School questionnaire for PISA 2012. http://pisa2012.acer.edu.au/downloads/ MS12_ScQ_ENG.pdf

Parcel, T.L. \& Dufur, J.M. (2001). Capital at home and at school: Effects on student achievement. Social Forces, 79(3), 881-911.

Psacharopoulos, G. (1990). Why educational policies can fail: An overview of selected African experiences. Discussion Paper No. 82. World Bank. 
Rockoff, J. E., (2004). The impact of individual teachers on student achievement: Evidence from panel data. American Economic Review, 94(2), 247-252.

Savaşçı, H. S. (2010). Sosyoekonomik değişkenlerin ve okulun eğitim kaynaklarının Illköğretim 7. Sinıf ögrencilerinin akademik başarı düzeyleri ile ilişki durumu. Yüksek Lisans Tezi, Mehmet Akif Ersoy Üniversitesi, Burdur.

Savaşç1, S. \& Tomul, E. (2013). The relationship between educational resources of school and academic achievement. International Education Studies, 6(4).

Shin, Y. \& Raudenbush, S.W. (2011). The causal effect of class size on academic achievement: Multivariate instrumental variable estimators with data missing at random. Journal of Educational and Behavioral Statistics, 36(2), 154-185. DOI: $10.3102 / 1076998610388632$

Rivkin, S. G., Hanushek, E. A., \& Kain, J. F. (2005). Teachers, schools and academic achievement. Econometrica, 73(2), 417-458. http://dx.doi.org/10.1111/j.1468$\underline{0262.2005 .00584 . x}$

Tansel, A. ve Bircan, F. (2006). Demand for education in Turkey: A tobit analysis of private tutoring expenditures. Economics of Education Review, 25(3), 303-313.

UNESCO (2007). Global monitoring report, education for all 2008. New York: Oxford Press.

Willms, D.J. \& Somers, M.A. (2001). Family, classroom and school effects on children's educational outcomes in Latin America. School Effectiveness and School Improvement, 12(4), 409-445.

Wößmann, L. (2003). Schooling resources, educational institutions and student performance: The international evidence. Oxford Bulletin of Economics and Statistics, 65(2), 117170. http://dx.doi.org/10.1111/1468-0084.00045

Yıldırım, A. ve Şimşek, H. (2008). Sosyal bilimlerde nitel araştırma yöntemleri. (7.Baskı). Ankara: Seçkin Yayıncılık. 